\title{
Sealing ability of AH26 and soft core gutta-percha using different instrumentations techniques and irrigations protocol: A SEM evaluation
}

\author{
Ferit Koçani, Blerim Kamberi, Edmond Dragusha
}

Dental Pathology and Endodontics, Faculty of Medicine/Stomatology, University of Prishtina, Prishtina, Kosovo

Email: ferit.kocani@uni-pr.edu

Received 21 March 2013; revised 26 April 2013; accepted 8 May 2013

Copyright (C) 2013 Ferit Koçani et al. This is an open access article distributed under the Creative Commons Attribution License, which permits unrestricted use, distribution, and reproduction in any medium, provided the original work is properly cited.

\begin{abstract}
Aim: The aim of this ex vivo study, with SEM, was to determine the effects of the smear layer on the root canal systems after different instrumentation technique and irrigation protocol, obturated with carrier based gutta-percha (Soft Core) and AH26 sealer. Materials \& Methods: Forty freshly extracted human teeth were used for this study. The teeth were divided into two major groups according to instrumentation technique (Manual and ProFile) and then each major group into four subgroups according to irrigation protocol (Saline solution, 17\% EDTA, 5.25\% NaOCl). All of the samples were obturated with AH26 and Soft Core Heating Gutta-percha. The evaluation of the objectives was performed using a Scanning Electron Microscope. Result: ProFile instrumentation followed with irrigation of $17 \%$ EDTA and $5.25 \%$ $\mathrm{NaOCl}$, selaed with AH26 Soft Core Heating Guttapercha provided maximal contact at the $S / D$ interface. The S/D interface had a serrated appearance due to effective penetration of the sealer into the patent dentin tubules. Conclusions: The adhezion of the respective sealer is more successful in cases when smear layer was removed completely.
\end{abstract}

Keywords: Smear Layer; Irrigation; AH26; Manual; ProFile; Sealer Adhesion

\section{INTRODUCTION}

Successful root canal therapy (RCT) relies on complete and accurate biomechanical preparation followed by a three dimensional obturation of the root canal systems in the absence of injury to periapical tissues [1]. The root filling is thought to be critical for the long-term outcome of root canal treatment $[2,3]$. A root filling may entomb the surviving bacteria, and prevent apical and coronal leakage, that is, stop influx of periapical tissue-derived fluid from nourishing the remaining microbiota and prevent re-infection of the root canal system [4]. Animal and human outcome studies have shown that the root filling materials and techniques used currently are not optimal, and fail to fulfill the desired requirements [5]. Therefore, the development and maintenance of a seal is desirable and considered a major prerequisite to improve the outcome of root canal treatment. One relatively recent approach to enhance the sealing ability of root fillings has been to apply adhesive concepts to endodontics $[6,7]$. Moreover, both apical and coronal leakage can occur following seemingly successful root canal treatment [8-10]. The intricate nature of root canal morphology complicates the instrumentation procedure [11]. Fins, anastomoses, isthmuses and other irregularities within the root canal system harbor tissue, microorganisms, and microbial by products that may lead to failure of root canal therapy [12]. On the other hand, microleakage of the root canal systems is a complex subject because many variables may influence it, such as root filling techniques, the physical and chemical properties of the sealers used and the smear layer [13]. Success of the smear layer removal depends on the instrumentation techniques employed and irrigation solvents used $[14,15]$. Sodium hypochlorite solution has been the commonly used irrigant, especially due to its effective antibacterial properties and its excellent action as an organic material solvent [16]. However, the use of only one irrigant is not sufficient to achieve smear layer removal. Many reports have demonstrated the decalcifying capacity of agents such as $10 \%-17 \%$ EDTA, 17\% ethylene glycol tetraacetic acid (EGTA) [17], MTAD (mixture of tetracycline isomer (doxycycline) [18], citric and maleic acid [19], and dimercaptosuccinic acid (DMSA) [20]). These agents bring about the remo- 
val of inorganic components and debris from the instrumented canals. The decalcifying efficacy of these acidic and chelating agents depends on the root length, application time, diffusion in the dentine and solution $\mathrm{pH}$ [1720].

The root canal filling must seal and prevent the ingress of organisms and tissue fluids into the root canal system [21]. The most common recommended obturation material is gutta-percha combined with a sealer [22-25]. Since gutta-percha is an impervious material, leakage through an obturated root canal system is most likely to occur at the sealer/dentin wall (S/D) and sealer/guttapercha (S/GP) interfaces $[7,22,26-30]$.

On the other hand, with the discovery of the smear layer [31] the knowledge on endodontic instruments has improved and the techniques have advanced. Based on the evaluation of the influence of smear layer on leakage, its removal was advocated in order to reduce micro leakage [26,32-39]. In contrast, many studies on instrumentation and obturation of the root canal systems demonstrate the difficulty (impossibility) to completely seal the root canal system [36]. Furthermore, interfacial micro leakage on S/D interface is demonstrated in different research $[9,22,24,32,34,36,40,41]$.

The aim of this ex vivo study, with SEM, was to determine the effects of the smear layer on adhesion of sealing material after manual and ProFile instrumentation, irrigation with $5.25 \%$ sodium hypochlorite and $17 \%$ EDTA, obturated with carrier based gutta-percha (Soft Core) and AH26 sealer.

\section{MATERIAL AND METHOD}

Forty freshly extracted human teeth were used for this study. They were preserved in saline solution. The samples consisted of upper incisors and mandibular premolars with single root canal. All the teeth were divided into two major groups according to instrumentation technique and then each major group was divided into four subgroups according to irrigation protocol. All of the samples were obturated with AH26 and Soft Core Heating Gutta-percha (Table 1).

Group 1: Samples were manually instrumented with K-file (Edenta, Switzerland). Subgroup 1.1. (Control) was irrigated with saline (DENTSPLY De Trey, GmbH, Germany). Subgroup 1.2. was irrigated with $5.25 \% \mathrm{NaOCl}$ (ADD Vision, Germany). Subgroup 1.3. was irrigated with 17\% EDTA (Calcinase, Lege Artis, Germany). Subgroup 1.4. was irrigated with $17 \%$ EDTA followed by $5.25 \%$ $\mathrm{NaOCl}$. All of the samples in the Group 1 were sealed and obturated with AH26 (DENTSPLY DeTrey GmbH, Germany) sealer and Soft-Core gutta-percha. Soft-Core ${ }^{\circledR}$ Oven (Soft-Core Dental Production Aps, Denmark) cones were used for the heating of gutta-percha.
Table 1. Sample distribution according to instrumentation technique, irrigation protocol, sealing material and core material.

\begin{tabular}{|c|c|c|}
\hline $\begin{array}{l}\text { Instrum. } \\
\text { Technique }\end{array}$ & 1. Manual & $\begin{array}{l}\text { 2. ProFile } \\
\text { /Series } 29,06 \text { taper }\end{array}$ \\
\hline \multirow{4}{*}{ Irrigation Protocol } & 1.1. Saline (control) & 2.1. Saline (control) \\
\hline & 1.2. $5.25 \% \mathrm{NaOCl}$ & 2.2. $5.25 \% \mathrm{NaOCl}$ \\
\hline & 1.3. $17 \%$ EDTA & 2.3. 17\% EDTA \\
\hline & $\begin{array}{l}\text { 1.4. } 5.25 \% \mathrm{NaOCl}+ \\
17 \% \text { EDTA }\end{array}$ & $\begin{array}{l}\text { 2.4. } 5.25 \% \mathrm{NaOCl}+ \\
\text { 17\% EDTA }\end{array}$ \\
\hline Sealer & AH26 & \\
\hline Core Material & Soft-Core & \\
\hline
\end{tabular}

Group 2: Samples were instrumented with Pro-File (Series 29, 06 taper, Tulsa Dental Products, Tulsa OK, USA) rotary instruments utilizing the crown-down technique with Endo-It hand piece (Aseptico Inc., USA) at $300 \mathrm{rpm}$ clockwise rotations, $240 \mathrm{gr} / \mathrm{cm}^{*}$. Subgroup 2.1. was irrigated with saline. Subgroup 2.2. was irrigated with $5.25 \% \mathrm{NaOCl}$. Subgroup 2.3. was irrigated with $17 \%$ EDTA. Subgroup 2.4. was irrigated with 17\% EDTA followed by $5.25 \% \mathrm{NaOCl}$. All of the samples in the Group 2 were sealed and obturated with AH26 sealer and SoftCore Singles gutta-percha (Soft-Core ${ }^{\circledR}$ Singles, a 3rd Generation Endodontic Obturator, Denmark). The scouting of the root canal was initiated with \#08 or \#10 K-files followed by the sequence of subsequent files and the final shape was achieved with \#40 or \#50 files depending on the size of the apical constriction and the root canal volume. Irrigating solutions were delivered via a 23gauge needle inserted into the canal without binding into the walls. The amount of the respective irrigation solution used per root canal was $7.5 \mathrm{ml}$. After instrumentation and irrigation, final rinse of the root canals was performed using distilled water to avoid continuing action of irrigating solutions. Root canals were dried with paper points before sealing. Lentulo spirals (Maillefer Instruments S.A., Switzerland) were used at low speed to coat the root canal walls for obturation. Soft-Core carrier based gutta-percha was used as a solid core material for obturation of all the samples. After cooling, the excess material was scared off at the cavo-surface margin. The teeth were stored in plastic containers filled with saline at room temperature for 24 hours. The resulting specimens were prepared for Scanning Electron Microscopy JEOL JSM-6335F (Tokyo, Japan) study. The blocks of teeth were cut with the ISOMET 11-1180 Low Speed SAW at the predetermined coronal, middle and the apical thirds. The cut samples were fixed in metallic blocks and put on the Sputter Coater S150 B EDWARDS for impregnation in gold $(\mathrm{Au})$ at 10 mbar pressure. After scanning and observing each third with the microscope, an image of the most representative area of that third was taken. Three 
pictures were obtained from each tooth, one for each third (apical, middle and coronal).

\section{RESULTS}

Group 1 (Manual Instrumentation): In the Subgroup 1.1. (Control subgroup) irrigated with saline, the smear layer was evident at the dentine/sealer (D/S) interface. The smear layer was equally distributed on every third of the root canal. Along with smear layer, debris was found in all samples of the control group. On visual inspection, the sealer/gutta-percha (S/GP) interface was linear and fully adhered with no interruption along the full length of the root. The contact of the sealer with the smear layer (where present) was weak and exhibiting voids at the interface in all control samples (Figure 1).

Subgroup 1.2. samples were irrigated with $5.25 \%$ $\mathrm{NaOCl}$ and they had a better contact at the S/GP rather than $\mathrm{S} / \mathrm{D}$ interface.

The S/D interface had no visible smear layer present that enabled full adhesion on SEM evaluation. The D/S interface had full linear appearance. The apical one third of all the samples in this subgroup had free debris particles visible and located in the S/D interface. Subgroup 1.3., irrigated with $17 \%$ EDTA, produced a smear layer that covered surfaces affected by instrumentation.

The S/D interface presented with voids throughout the root length while S/GP interface had a full linear adhesion on SEM evaluation. Subgroup 1.4., irrigated with $5.25 \mathrm{NaOCl}$ and $17 \%$ EDTA had a maximum, linear and continual contact at the S/D interface with no smear layer in between. At the coronal one third of the root, the sealer had a maximum contact with the dentin wall, the dentinal tubules were visible and patent. The contact at this interface was linear with a tendency for sealer to penetrate patent dentinal tubules. The sealer at the $\mathrm{D} / \mathrm{S}$ and

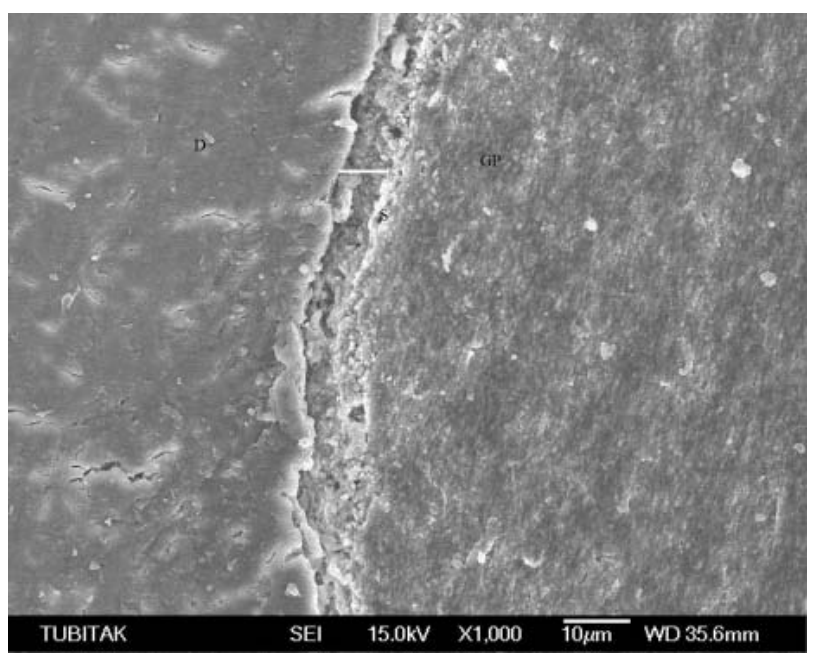

Figure 1. The contact of the sealer (S) with the dentine (D), exhibiting voids at the interface.
D/GP intefaces was visually compact with no voids.

The middle one third of the roots had also good contact with no smear layer in between. Patent dentin tubules were visible with some of them being pentrated by sealer "pluggs". The S/GP interface was linear and continual while the S/D interface was serrated. This shape of contact at the $\mathrm{S} / \mathrm{D}$ interface is a result of absence of smear layer at the dentin surface of the root canal. At the apical one third of the root the adhesion at S/D interface was weaker due to the derbis present at this level. The $\mathrm{S} / \mathrm{GP}$ interface was liner and continual as opposed to the $\mathrm{S} / \mathrm{D}$ interface that was interrupted in several areas along the apical third of the root canal (Figure 2).

Group 2 (ProFile Instrumentation): Subgroup 2.1. (Control subgroup) irrigated with saline, at the coronal one third of the root canal the S/D interface had a weaker adhesion contact with visible voids, while the S/GP interface had a full linear contact. At the middle and apical one third, the S/D interface had voids throughout these root levels and its volume. The S/GP interface had full adhesion on SEM evaluation. Subgroup 2.2. irrigated with $5.25 \% \mathrm{NaOCl}$ on the instrumented surfaces of the root canal walls produced a smear layer which covered dentin tubules. The S/GP interface had full linear adhesion with no voids visible on SEM throughout the length of the root. The S/D interface at the coronal one third was linear with some penetration of the sealer into the patent tubules. At the middle and apical one third of the root, the contact at this interface showed voids filled with free debris particles.

Subgroup 2.3. Irrigated with 17\% EDTA on SEM evaluation showed smear layers in between the S/D interface. The contact at the S/GP interface had full adhesion at all levels of the root. The voids at the S/D interface with smear layer present are more visible at the middle and apical thirds of the root along with remaining debris.

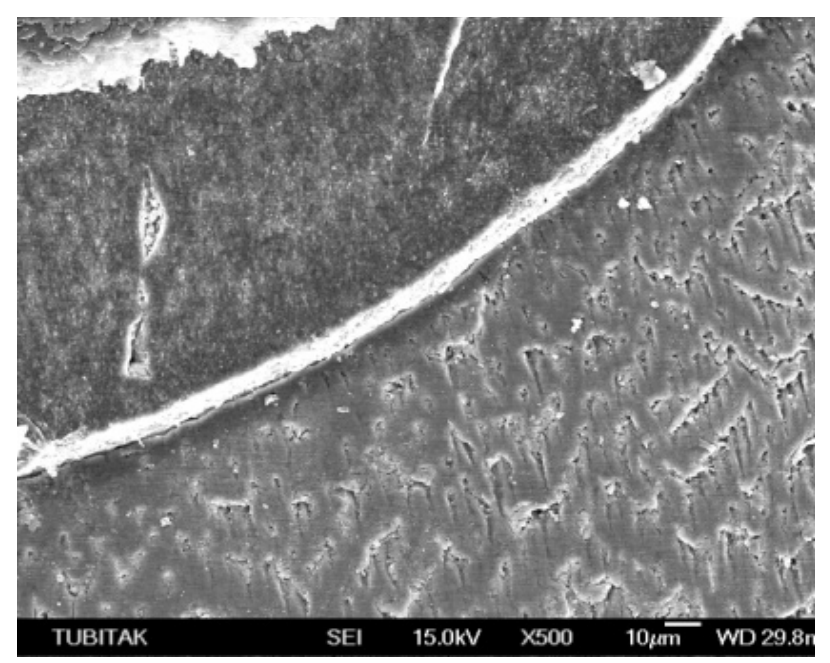

Figure 2. The sealer at the $\mathrm{D} / \mathrm{S}$ and $\mathrm{D} / \mathrm{GP}$ intefaces is visually compact with no voids. 
Subroup 2.4. irrigated with $17 \%$ EDTA and $5.25 \%$ $\mathrm{NaOCl}$ provided best, maximal contact at the S/D interface. (Figure 3). The visual appearance of the S/D interface was linear with absence of smear layer that was efficiently removed with this irrigation protocol.

The S/D interface had a serrated appearance due to effective penetration of the sealer into the patent dentin tubules. The S/GP interface was linear at full length of the coronal and middle two thirds of the root. At the apical one third of the root, free debris particles that weaken the adhesion at the S/D interface were evident, as demonstrated with SEM evaluation.

\section{DISCUSSION}

White [42] studied the penetration of the obturation material into the dentine tubules using scanning electron microscope techniques. In his study, canals were sealed with silicone and gutta-percha using cold lateral condensation technique. The penetration of the obturation material was more evident in the areas of dentinal walls with no smear layer. Saleh [26] with EDS, followed the dispersion of the sealing material and the contact with dentine walls. The results show that when the smear layer was removed, penetration of the sealing material in dentine tubules was evident. In some cases when there was no penetration of the sealing material in the dentine walls the thickness of the material/paste was in form of bonding fat system, in contrast to those cases were the penetration of tubules was evident the sealer layer was very thin. On the other hand, instrumentation and irrigation with 17\% EDTA and $5.25 \% \mathrm{NaOCl}$, sealed with AH26, CRCS and RSA with lateral condensation of gutta-percha [43], showed that AH26 achieved the best adaptation and deepest penetration into dentine tubules. Also, is demonstrated ad-

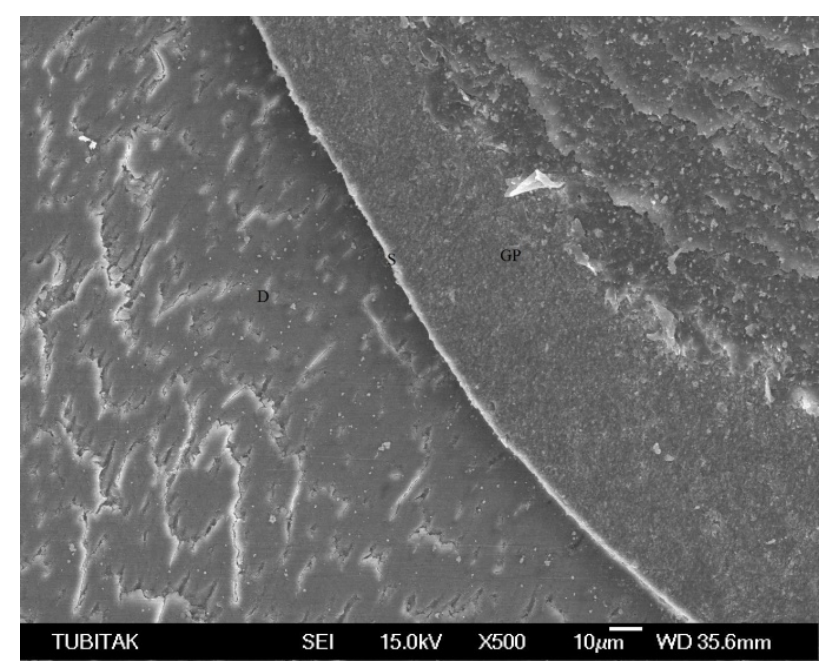

Figure 3. The appearance of the S/D interface is linear with absence of smear layer that was efficiently removed with irrigation protocol. hesive superiority of AH26/ silverfree sealer at the apical third of the root canal using methylen blu penetration method $[24,45]$. Soussa [45] evaluated the adhesive properties of Sealapex, Sealer 26, N-Rickert, and Endofill sealers with dye penetration method when irrigating with EDTA, EGTA and CDTA. Dye penetration was measured with a stereomicrocope. They found no correlation between the test for adhesiveness and microleakage since irrigation alone is insufficient for successful removal of smear layer from dentinal walls. Schafer [46] investigated the cleaning effectiveness of hand (K-Flexofiles) and automated instrumentation (Ni-Ti ProFile system). Complete cleanliness (debris and smear layer) was not achived by any of the techniques. As well instrumentation result, especially in curved canals, were obtained with rotary ProFile instruments. Hulsman [47] compared root canal preparation using two different rotary Ni-Ti instruments, Hero 642 and Quantec. SEM evaluation of cleaning ability, Hero 642 achieved better result on removing debris and smear layer. Versumer [48] compared several parameters of root canal preparation using two different rotary Ni-Ti instruments, ProFile 0.04 were used in crowndown whereas LightSpeed in step-back technique. For debris and smear layer removal, in the coronal third of the root canal LightSpeed performed significantly better result than ProFile. In the middle and apical thirds the differences were not significant. Both Ni-Ti systems maintened the original canal curvature well, with no statistical singificance between group. Mayer [49] studied the influence of two rotary preparation technique on cleanliness of the shaped canals, ProFile 0.04 and LightSpeed, and evaluated debris and smear scores after ultrasonically activated irrigants during canal preparation. All groups were irrigated using $5.25 \% \mathrm{NaOCl}$ and $17 \%$ EDTA. Research results show that regardless what instrumentation technique is used for root canal treatment, the smear layer will be present and covering the dentin throughut the root canal length if saline is used as an irrgation solution [50-52]. The ability to efectively clean the root canal space depends on the irrigation solution and instrumentation technique [53].

Current design of endodontic instruments influence the efficiency to remove the debris and smear layer [54]. More recent research has shown that cleaning can be sig- nificantly improved once the shaping procedure has been completed [55]. The results of the study showed that GTTM rotary instrumentation followed by a specific final irrigation sequence could produce good clean canals. In majority of cases, canal surfaces were smooth and free of pulpal remnants [56]. Use of the rotary instrumentation resulted in a substantial amount of smear layer production. This smear layer consists of dentine particles and pulp tissue densly compacted against the 
root canal wall and extending into the dentinal tubules $[50,52]$. The smear layer produced by instrumentation should be removed because it increases microleakage at the S/D interface. Shaping procedures can be completed more easily, quickly and predictably. However, effective cleaning of the entire root canal system using Ni-Ti rotary instruments has not yet been demonstrated [57]. Comparisons between rotary NiTi instruments and stainless steel hand instruments suggest that the manual technique with stainless steel instruments results in an equivalent cleaning ability [58] or even better performance, with significantly less residual debris [59]. Another study showed significantly less smear layer and pulpal debris remaining in the apical third of the root canal compared with coronal and middle thirds, with similar results to the conventional manual technique using stainless steel files or NiTi instruments $[58,60]$. Rotary NiTi instrumentation of root canals have a superior ability of preserving the original root curvatures [61], however a recent study revealed no statistical differences between rotary NiTi instruments and stainless steel hand instrumentation technique of root canal [62]. Rotary NiTi instruments have significantly better centering ability and decrease the prevalence and degree of transportation and straightening compared with hand instrumentation technique of root canal $[63,64]$. Different rotary NiTi systems indicated large untreated areas on the canal wall, these areas tended to be on the convex curvature at midroot and the concave side of the curvature more apically [65]. Irrigants have a predominant role in successful removal of debris and root canal disinfection. Irrigation of root canal space with $\mathrm{NaOCl}$ at different concentrations is insufficinet for removal of the smear layer regardless of the instrumentation technique. Irrigation with 17\% EDTA, creates a smear layer with homogenous appearance that completely covers the root canal dentine regardless of the instrumentation technique [66].

\section{CONCLUSIONS}

Considering that the adhesion of a sealer is directly poportional to the traction tension, that adhesion will be as great as the force necessary to displace the sample containing the sealer. Adhesion to a root canal sealer means its capacity to attach to the dentinal walls of the root canal and provide bonding between it and gutta-percha points.

Conclusivelly, it may be said that the removal of smear layer is possible if irrigation is done with a combination of two solutions (17\% EDTA and $5.25 \% \mathrm{NaOCl}$ ), regardless of the instrumentation technique. Hence the adhesion of the respective sealer is more successful in cases when smear layer is removed completely.

\section{CLINICAL SIGNIFICANCE}

Smear layer contains inorganic and organic substances as well as fragments of odontoblastic processes, microorganisms an necrotic debris. Elimination or significant reduction of irritants from the root canal system is the essential elements for successful outcomes.

\section{REFERENCES}

[1] Schilder, H. (1967) Filling root canals in three dimensions. Dental Clinics of North America, 11, 723-744.

[2] Sjögren, U., Hägglund, B., Sundqvist, G. and Wing, K. (1990) Factors affecting the long-term results of endodontic treatment. Journal of Endodontics, 16, 498-504. doi:10.1016/S0099-2399(07)80180-4

[3] Buckley, M. and Spangberg, W. (1995) The prevalence and technical quality of endodontic treatment in an American subpopulation. Oral Surgery, Oral Medicine, Oral Pathology, Oral Radiology and Endodontology, 79, 92100.

[4] Sundqvist, G., Figdor, D., Persson, S. and Sjögren, U. (1998) Microbiologic analysis of teeth with failed endodontic treatment and the outcome of conservative re-treatment. Oral Surgery, Oral Medicine, Oral Pathology, Oral Radiology and Endodontology, 85, 86-93. doi:10.1016/S1079-2104(98)90404-8

[5] Katebzadeh, N., Hupp, J. and Trope, M. (1999) Histological periapical repair after obturation of infected root canals in dogs. Journal of Endodontics, 25, 364-368. doi:10.1016/S0099-2399(06)81173-8

[6] Leonard, J.E., Gutmann, J.L. and Guo, I.Y. (1996) Apical and coronal seal of roots obturated with a dentine bonding agent and resin. International Endodontic Journal, 29, 76-83. doi:10.1111/j.1365-2591.1996.tb01165.x

[7] Mannocci, F. and Ferrari, M. (1998) Apical seal of roots obturated with laterally condensed gutta-percha, epoxy resin cement, and dentin bonding agent. Journal of Endodontics, 24, 41-44. doi:10.1016/S0099-2399(98)80212-4

[8] Ricucci, D. and Langeland, K. (1998) Apical limit of root canal instrumentation and obturation, part 2. Histological study. International Endodontic Journal, 31, 394-409. doi:10.1046/j.1365-2591.1998.00183.x

[9] Pommel, L., Jacquot, B. and Camps, J. (2001) Lack of Correlation among three methods for evaluation of apical leakage. Journal of Endodontics, 27, 347-350. doi:10.1097/00004770-200105000-00010

[10] Cobankara, F.K., Orucoglu, H., Sengun, A. and Belli, S. (2006) The quantitative evaluation of apical sealing of four endodontic sealers. Journal of Endodontics, 32, 6668. doi:10.1016/j.joen.2005.10.019

[11] Frank, J.V. (1984) Root canal anatomy of the human permanent teeth. Oral Surgery, Oral Medicine, Oral Pathology, 58, 589-599. doi:10.1016/0030-4220(84)90085-9

[12] Çalişkan, M.K., Pehlivan, Y., Sepetçioğlu, F., Türkün, M. and Tuncer, S.Ş. (1995) Root canal morphology of human permanent teeth in a Turkish population. Journal of 
Endodontics, 21, 200-204. doi:10.1016/S0099-2399(06)80566-2

[13] White, R.R., Goldman, M. and Lin, P.S. (1984) The influence of the smeared layer upon dentinal tubule penetration by plastic filling materials. Journal of Endodontics, 10, 558-562. doi:10.1016/S0099-2399(84)80100-4

[14] Koçani, F., Kamberi, B., Dragusha, E., Mrasori, S. and Haliti, F. (2012) The cleaning efficiency of the root canal after different instrumentation technique and irrigation protocol: A SEM analysis. Open Journal of Stomatology, 2, 69-76.

[15] Koçani, F., Kamberi, B. and Dragusha, E. (2012) Manual sonic-air and ultrasonic instrumentation of root canal and irrigation with 5.25\% sodium hypochlorite and 17\% Ethylenediaminetetraacetic acid: A scanning electron microscope study. Journal of Conservative Dentistry, 15, 118122. doi:10.4103/0972-0707.94575

[16] Moorer, W.R. and Wesselink, P.R. (1982) Factors promoting the tissue dissolving capability of sodium hypochlorite. International Endodontic Journal, 15, 187-196. doi:10.1111/j.1365-2591.1982.tb01277.x

[17] Sudha, R., Sukumaran, V.R., Ranganathan, J. and Bharadwaj, N. (2006) Comparative evaluation of the effect of two different concentrations of EDTA at two different PH and time periods on root dentin. Journal of Conservative Dentistry, 9, 36-42. doi:10.4103/0972-0707.41307

[18] Torabinejad, M., Khademi, A.A., Babagoli, J., Cho, Y., Johnson, W.B., Bozhilov, K., et al. (2003) A new solution for the removal of smear layer. Journal of Endodontology, 29, 170-175. doi:10.1097/00004770-200303000-00002

[19] Ballal, N.V., Kandian, S., Mala, K., Bhat, K.S. and Acharya, S. (2009) Comparison of the efficacy of maleic acid and ethylenediaminetetraacetic acid in smear layer removal from instrumented human root canal: A scanning electron microscopic study. Journal of Endodontology, 35, 1573-1576. doi:10.1016/j.joen.2009.07.021

[20] Rai, B., Jain, R., Kharb, S., Miglani, S. and Anand, S.C. (2006) Comparative anti-microbial activity of $15 \%$ EDTA and $15 \%$ dimercaptosuccinic acid (DMSA). Journal of Conservative Dentistry, 9, 32-35. doi:10.4103/0972-0707.41306

[21] Goldberg, F., Bernat, M.I., Spielberg, C., Massone, E.J. and Piovano, S.A. (1985) Analysis of the effect of ethylenediaminetetraacetic acid on the apical seal of root canal fillings. Journal of Endodontics, 11, 544-547. doi:10.1016/S0099-2399(85)80200-4

[22] Lares, C. and ElDeeb, M.E. (1990) The sealing ability of the thermafil obturation technique. Journal of endodontics, 16, 474-479. doi:10.1016/S0099-2399(07)80176-2

[23] Gençoğlu, N., Samani, S. and Günday, M. (1993) Dentinal wall adaptation of thermoplasticized gutta-percha in the absence or presence of smear layer: A scanning electron microscopic study. Journal of Endodontics, 19, 558562. doi:10.1016/S0099-2399(06)81286-0

[24] Lee, K.-W., Williams, M.C., Camps, J.J. and Pashley, D.H. (2002) Adhesion of endodontic sealers to dentin and gutta-percha. Journal of Endodontics, 28, 684-688.

\section{doi:10.1097/00004770-200210000-00002}

[25] Zielinski, T.M., Baumgartner, J.C. and Marshall, J.G. (2008) An evaluation of gutta flow and gutta-percha in the filling of lateral grooves and depressions. Journal of Endodontics, 34, 295-298. doi:10.1016/j.joen.2007.12.004

[26] Saleh, I.M., Ruyter, I.E., Haapasalo, M.P. and Ørstavik, D. (2003) Adhesion of endodontic sealers: Scanning electron microscopy and energy dispersive spectroscopy. Journal of Endodontics, 29, 595-601. doi:10.1097/00004770-200309000-00013

[27] Limkangwalmongkol, S., Burtscher, P., Abbott, P.V., Sandler, A.B. and Bishop, B.M. (1991) A comparative study of the apical leakage of four root canal sealers and laterally condensed gutta-percha. Journal of Endodontics, 17, 495-499. doi:10.1016/S0099-2399(06)81797-8

[28] Oguntebi, B.R. and Shen, C. (1992) Effect of different sealers on thermoplasticized gutta-percha root canal obturations. Journal of Endodontics, 18, 363-366. doi:10.1016/S0099-2399(06)81219-7

[29] Wu, M.-K., De Gee, A.J. and Wesselink, P.R. (1997) Leakage of AH26 and ketac-endo used with injected warm gutta-percha. Journal of Endodontics, 23, 331-334. doi:10.1016/S0099-2399(97)80417-7

[30] Nagas, E., Altundasar, E. and Serper, A. (2009) The effect of master point taper on bond strength and apical sealing ability of different root canal sealers. Oral Surgery, Oral Medicine, Oral Pathology, Oral Radiology, and Endodontology, 107, e61-e4. doi:10.1016/j.tripleo.2008.09.020

[31] Mc Comb, D. and Smith, C. (1975) A preliminary scanning electron microscopy study of root after endodontic procedures. Journal of Endodontics, 1, 238-242. doi:10.1016/S0099-2399(75)80226-3

[32] Lester, K.S. and Boyde, A. (1977) Scaning electron microscopy of instrumented, irigated and filled root canals. British Dental Journal, 143, 359-367. doi:10.1038/sj.bdj.4804007

[33] Goldman, M., Goldman, L.B., Cavaleri, R., Bogis, J. and Sun, L.P. (1982) The efficacy of several endodontic irrigating solutions: A scanning electron microscopic study: Part 2. Journal of endodontics, 8, 487-492. doi:10.1016/S0099-2399(82)80073-3

[34] Evans, J.T. and Simon, J.H.S. (1986) Evaluation of the apical seal produced by injected thermoplasticized guttapercha in the absence of smear layer and root canal sealer. Journal of Endodontics, 12, 101-107. doi:10.1016/S0099-2399(86)80299-0

[35] Goldman, M., Goldman, L.B., Cavaleri, R., Bogis, J. and Lin, P.S. (1982) The efficacy of several endodontic irrigating solutions: A scanning electron microscopic study: Part 2. Journal of National Cancer Institute, 8, 487-492. doi:10.1016/S0099-2399(82)80073-3

[36] Gettleman, B.H., Messer, H.H. and ElDeeb, M.E. (1991) Adhesion of sealer cements to dentin with and without the smear layer. Journal of Endodontics, 17, 15-20. doi:10.1016/S0099-2399(07)80155-5

[37] Georgopoulou, M.K., Wu, M.-K., Nikolaou, A. and Wes- 
selink, P.R. (1995) Effect of thickness on the sealing ability of some root canal sealers. Oral Surgery, Oral Medicine, Oral Pathology, Oral Radiology, and Endodontology, 80, 338-344. doi:10.1016/S1079-2104(05)80392-0

[38] Kokkas, A.B, Boutsioukis, A.C., Vassiliadis, L.P. and Stavrianos, C.K. (2004) The influence of the smear layer on dentinal tubule penetration depth by three different root canal sealers: An in vitro study. Journal of Endodontics, 30, 100-102.

doi:10.1097/00004770-200402000-00009

[39] Ordinola-Zapata, R., Bramante, C.M., Graeff, M.S.Z., et al. (2009) Depth and percentage of penetration of endodontic sealers into dentinal tubules after root canal obturation using a lateral compaction technique: A confocal laser scanning microscopy study. Oral Surgery, Oral Medicine, Oral Pathology, Oral Radiology, and Endodontology, 108, 450-457. doi:10.1016/j.tripleo.2009.04.024

[40] Oruçoğlu, H., Sengun, A. and Yilmaz, N. (2005) Apical leakage of resin based root canal sealers with a new computerized fluid filtration meter. Journal of Endodontics, 31, 886-890. doi:10.1097/01.don.0000164134.79052.b3

[41] Özok, A.R., Van Der Sluis, L.W.M., Wu, M.-K. and Wesselink, P.R. (2008) Sealing ability of a new polydimethylsiloxane-based root canal filling material. Journal of Endodontics, 34, 204-207. doi:10.1016/S0099-2399(87)80195-4

[42] White, R.R., Goldman, M. and Lin, P.S. (1987) The influence of the smeared layer upon dentinal tubule penetration by endodontic filling materials. Part II. Journal of Endodontics, 13, 369-374. doi:10.1046/j.1365-2842.2003.01084.x

[43] Sevimay, S. and Dalat, D. (2002) Evaluation of penetration and adaptation of three different sealers: A SEM study. Journal of Oral Rehabilitation, 30, 951-955. doi:10.1046/j.1365-2842.2003.01084.x

[44] Suprabha, B., Sudha, P. and Vidya, M. (2002) A comparative evaluation of sealing ability of root canal sealers. Indian Journal of Dental Research, 13, 31-36.

[45] Sousa-Neto, M., Passarinho-Neto, J., Carvalho-Junior, J., Cruz-Filho, A., Pecora, J. and Saquy P. (2002) Evaluation of the effect of EDTA, EGTA and CDTA on dentin adhesiveness and microleakage with different root canal sealers. Brazilian Dental Journal, 13, 123-128. doi:10.1590/S0103-64402002000200009

[46] Schäfer, E. and Zapke, K. (2000) A comparative scanning electron microscopic investigation of the efficacy of manual and automated instrumentation of root canals. Journal of Endodontics, 26, 660-664. doi:10.1097/00004770-200011000-00007

[47] Hülsmann, M., Schade, M. and Schäfers, F. (2001) A comparative study of root canal preparation with HERO 642 and Quantec SC rotary Ni-Ti instruments. International Endodontic Journal, 34, 538-546. doi:10.1046/j.1365-2591.2001.00431.x

[48] Versümer, J., Hülsmann, M. and Schäfers, F. (2002) A comparative study of root canal preparation using ProFile.04 and Lightspeed rotary Ni-Ti instruments. Interna- tional Endodontic Journal, 35, 37-46. doi:10.1046/j.1365-2591.2002.00454.x

[49] Mayer, B.E., Peters, O.A. and Barbakow, F. (2002) Effects of rotary instruments and ultrasonic irrigation on debris and smear layer scores: a scanning electron microscopic study. International Endodontic Journal, 35, 582589. doi:10.1046/j.1365-2591.2002.00502.x

[50] McComb, D. and Smith, C. (1975) A preliminary scanning electron microscopy study of root after endodontic procedures. Journal of Endodontics, 1, 238-242. doi:10.1016/S0099-2399(75)80226-3

[51] Goldman, L., Goldman, M. and Kronman, J. (1981) The efficacy of several irrigating solutions for endodontics: A scanning electron microscopic study. Oral Surgery, 52, 197-204. doi:10.1016/0030-4220(81)90319-4

[52] Mader, C., Baumgartner, J. and Peters, D. (1984) Scanning electron microscopic investigation of the smeared layer on root canal walls. Journal of Endodontics, 10, 477-483. doi:10.1016/S0099-2399(84)80204-6

[53] Thompson, S. and Dummer, P. (1997) Shaping ability of ProFile.04 Taper Series 29 rotary nickel-titanium instruments in simulated root canals. International Endodontic Journal, 30, 8-15.

[54] Bertrand, M., Pizzardini, P., Muller, M., Médioni, E. and Rocca, J. (1999) The removal of the smear layer using the Quantec system. A study using scanning electron microscope. International Endodontic Journal, 32, 217-224. doi:10.1046/j.1365-2591.1999.00231.x

[55] Gambarini, G. (1999) Shaping and cleaning the root canal system: A scanning electron microscopic evaluation of a new instrumentation and irrigation technique. Journal of Endodontics, 25, 800-803. doi:10.1016/S0099-2399(99)80300-8

[56] Gambarini, G. and Laszkiewicz, J.A. (2002) scanning electron microscopic study of debris and smear layer remaining following use of GT rotary instruments. International Endodontic Journal, 35, 422-427. doi:10.1046/j.1365-2591.2002.00495.x

[57] Siqueira, J.J., Araújo, P., Garcia, P., Fraga, R. and Sabóia Dantas, C. (1997) Histological evaluation of the effectiveness of five instrumentation techniques for cleaning the apical third of root canals. Journal of Endodontics, 23, 499-502. doi:10.1016/S0099-2399(97)80309-3

[58] Prati C, Foschi F, Nucci C, Montebugnoli L and Marcionni S. (2004) Appearance of the root canal walls after preparation with NiTi rotary instruments: A comparative SEM investigation. Clinical Oral Investigations, 8, 102110. doi:10.1007/s00784-004-0253-8

[59] Ahlquist, M., Henningsonn, O., Hultenby, K. and Ohlin, J. (2001) The effectiveness of manual and rotary technique in the cleaning of root canals: A scanning electron microscopy study. International Endodontic Journal, 34, 533-537. doi:10.1046/j.1365-2591.2001.00429.x

[60] Foschi, F., Nucci, C., Montebugnoli, L., Marchionni, S., Breschi, L. and Malagnino, V. (2004) SEM evaluation of canal wall dentine following use of Mtwo and ProTaper NiTi rotary instruments. International Endodontic Journal, 37, 832-829. doi:10.1111/j.1365-2591.2004.00887.x 
[61] Schafer, E. and Schlingemann, R. (2003) Efficiency of rotary nickel-titanium FlexMaster instruments compared with stainless steel hand K-Flexofile. Part 2. Cleaning effectiveness and instrumentation result in severely curved root canals of extracted teeth. International Endodontic Journal, 35, 514-521. doi:10.1046/j.1365-2591.2002.00515.x

[62] Guelzow, A., Stamm, O., Martus, P. and Kielbassa, A. (2005) Comparative study of six rotary nickel-titanium systems and hand instrumentation for root canal preparation International Endodontic Journal, 38, 743-752. doi:10.1111/j.1365-2591.2005.01010.x

[63] Yoshimine, Y., Ono, M. and Akamine, A. (2005) The shaping effects of three nickel-titanium rotary instruments in simulated S-shaped canals. Journal of Endodontology, 31, 373-375. doi:10.1097/01.don.0000140568.40462.43

[64] Iqbal, M., Firic, S., Tulcan, J., karabucak, B. and Kim, S. (2004) Comparision of apical transportation between ProFile and ProTaper NiTi rotary instruments. International Endodontic Journal, 37, 359-364. doi:10.1111/j.1365-2591.2004.00792.x

[65] Peters, O., Peters, C., Schonenberger, K. and Barbakow, F. (2003) ProTaper rotary root canal preparation: Effect of canal anatomy on final shape analyzed by micro CT. International Endodontic Journal, 36, 86-92. doi:10.1046/j.1365-2591.2003.00626.x

[66] Baumgartner, J. and Mader, C. (1987) A scanning electron microscopic evaluation of four root canal irrigation regimens. Journal of Endodontics, 13, 147-157. doi:10.1016/S0099-2399(87)80132-2 